\title{
An individual participant data (IPD) meta-analysis on the attachment network to
} multiple caregivers

\author{
Protocol* \\ *This protocol consists of all Preregistration of Secondary Data Analysis items recommended by OSF \\ (https://osf.io/jqxfz/)
}

Conducted by the Collaboration on Attachment to Multiple Parents and Outcomes Synthesis (CAMPOS)

January 2020

CC-By Attribution 4.0 International 
Collaboration for Attachment to Multiple Parents and Outcomes Synthesis

\section{Project coordination}

Collaboration on Attachment Research Synthesis

Clinical Child and Family Studies

Van der Boechorststraat 7

1081 BT Amsterdam

The Netherlands

For enquiries please contact:

Or Dagan

e-mail: or.dagan@stonybrook.edu

tel: +1 646-270-1100

Marije Verhage

e-mail: m.l.verhage@vu.nl

tel: $+31(0) 205988882$

Carlo Schuengel

e-mail: c.schuengel@vu.nl

tel: $+31(0) 205988905$

\section{Core members}

(in alphabetical order)

M. J. Bakermans-Kranenburg, Clinical Child and Family Studies, Vrije Universiteit, Amsterdam, The Netherlands

K. Bernard, Department of Psychology, Stony Brook University, USA

O. Dagan, Department of Psychology, Stony Brook University, USA

R. Duschinsky, Department of Public Health and Primary Care, University of Cambridge, Cambridge, UK

R. M. P. Fearon, University College London and The Anna Freud Centre, London, UK

S. Madigan, Department of Pediatrics, Hospital for Sick Children, Toronto, Canada

M. Oosterman, Clinical Child and Family Studies, VU University, Amsterdam, The Netherlands

G. I. Roisman, Institute of Child Development, University of Minnesota, USA

A. Sagi-Schwartz, Center for the Study of Child Development, Haifa, Israel

C. Schuengel, Clinical Child and Family Studies, Vrije Universiteit Amsterdam, The Netherlands

M. H. van IJzendoorn, Department of Psychology, Education, and Child Studies, Erasmus University

Rotterdam, The Netherlands

M. L. Verhage, Clinical Child and Family Studies, Vrije Universiteit, Amsterdam, The Netherlands 


\section{Contents}

$\begin{array}{ll}\text { Introduction } & 4\end{array}$

$\begin{array}{lr}\text { Research questions } & 6\end{array}$

$\begin{array}{ll}\text { Hypothesis-testing } & 6\end{array}$

$\begin{array}{ll}\text { Exploratory research questions } & 7\end{array}$

General methods $\quad 9$

Objectives $\quad 9$

Harmonization of developmental outcome measures $\quad 9$

$\begin{array}{ll}\text { Eligibility criteria } & 10\end{array}$

$\begin{array}{ll}\text { Identification of studies } & 10\end{array}$

$\begin{array}{ll}\text { Data collection } & 10\end{array}$

Main analyses 12

Sensitivity analyses $\quad 13$

Project coordination $\quad 13$

$\begin{array}{ll}\text { Timetable } & 14\end{array}$

$\begin{array}{ll}\text { Privacy policy } & 14\end{array}$

$\begin{array}{ll}\text { Publication policy } & 14\end{array}$

Appendix A - Search term $\quad 15$

Appendix B - Provisional list of eligible studies 16

Appendix C: Figure $1 \quad 19$

Appendix D: Table 120

$\begin{array}{ll}\text { References } & 21\end{array}$ 


\section{Introduction}

According to attachment theory, infants form selective attachment relationships through repeated interactions with their parents or other primary caregivers (Bowlby, 1969). Infants develop secure attachment relationships when parents are available and responsive in times of distress; in turn, infants with secure attachment relationships derive a sense of safety from physical or perceived proximity to caregivers when facing distress. However, when parents respond insensitively to children's distress, by being hostile or punitive, intrusive, inconsistent, or unresponsive, children are likely to develop insecure attachment patterns (Ainsworth, Blehar, Waters, \& Wall, 1978)- that is, either an insecure-avoidant attachment, characterized by turning away from one's caregiver in times of need, or an insecureresistant attachment, characterized by expressing anger or resistance towards one's caregiver simultaneously with proximity-seeking (Ainsworth et al., 1978; Main, 2000). These 'organized' attachment patterns of secure and insecure attachment behavior have been thought of as consistent strategies to maximize proximity to the caregiver at times of distress (Main, 2000). This is in contrast to disorganized attachment behaviour, which has been linked to alarming behaviours by caregivers (Cyr, Euser, Bakermans-Kranenburg, \& Van IJzendoorn, 2010; Schuengel, Bakermans-Kranenburg, \& Van IJzendoorn, 1999). As such, disorganized attachment behaviors reflect a disruption of attachment behavior strategies (Main \& Solomon, 1990), presumably stemming from the paradox between the parent's role as a haven of safety and simultaneously as a source of alarm (Hesse \& Main, 2006). Over time, attachment patterns influence an array of long-term developmental outcomes, including psychological functioning (as elaborated below) and physiological regulation (Cassidy, Jones, \& Shaver, 2013).

Although early studies have acknowledged the role of both parents in child rearing, their predominant focus on mother-infant relationships was influenced by cultural values about caregiving roles, and also by the theoretical concept of "monotropy" (Bowlby, 1951, 1988). Bowlby actually intended the term "monotropy" to denote infants' inborn tendency to seek proximity to familiar caregivers, providing a building block for the formation of attachment relationships (Duschinsky, 2020). However, understandably the prefix 'mono' was generally taken, erroneously, to imply that only one person, usually the mother, is an important attachment figure, whereas other caretakers are at most subsidiary attachment figures with a marginal influence on the child's development. Moreover, the evolutionary psychological idea that children may prefer to turn to a single primary caregiver at times of need to promote efficiency in soliciting prompt and successful support, thus conferring advantages in human phylogeny (Cassidy, 2016), makes it plausible that one caregiver may be singled out as most important. Nevertheless, research has shown that infants form attachment relationships with at least two caregivers (most often, mothers and fathers) simultaneously and independently (Easterbrooks \& Goldberg, 1984; Grossmann, Grossmann, Huber, \& Wartner, 1981; Grossmann et al., 2002; Lamb, Hwang, Frodi, \& Frodi, 1982; Main, Kaplan, \& Cassidy, 1985; Sagi-Schwartz \& Aviezer, 2005). Accordingly, Van IJzendoorn, Sagi, and Lambermon (1992) raised the following question: Given that infants simultaneously form independent attachment relationships with mothers and fathers, how can infant attachment to only one caregiver, usually the mother, predict developmental outcomes?

Studies evaluating integrative effects of infant's attachment to mother and father on later life functioning are still scarce. Moreover, in spite of the fact that infant disorganized attachment to one parent was shown to be a significant predictor of multiple key developmental outcomes (e.g., Cooke, Kochendorfer, Stuart-Parrigon, Koehn, \& Kerns, 2018; Groh et al., 2014; Pallini et al., 2018; Van IJzendoorn, Dijkstra, \& Bus, 1995), no study has yet addressed outcomes associated with different disorganization status configurations with mothers and fathers. This, perhaps, also has to do with a tacit reification of attachment classifications among researchers, so that - even if this was contrary to theory - 
in practice they have been functionally treated as quasi-personality variables (Morris 2013); as such, assessment of attachment disorganization with another caregiver may have been implicitly deemed redundant (to researchers or funders of research) given that assessment with one caregiver would already have brought to light the personality (rather than the relationship specific aspect) of the developing child. Another contributing factor may have been the relatively late emergence of the disorganization classification, which became routinely used after all but one of the infant attachment network studies were published (Grossmann et al., 2002; Main \& Weston, 1981; Suess, Grossmann, \& Sroufe, 1992; Van IJzendoorn, Sagi, \& Lambermon, 1992).

Beyond any empirical considerations, assessing infants' multiple attachment relationships is an important endeavor to pursue due to the fact that it constitutes a more ecologically valid approach to evaluating the social context of development than only assessing a single relationship (Belsky, 1981). A move from the traditional view of dyadic, infant-mother attachment approach to the triadic, infantmother and infant-father framework was recommended decades ago (e.g., Belsky, 1981; Cowan, 1997; Kozlowska \& Hanney, 2002). However, attachment theory has yet to offer a robust reply to the call for this family-based approach to child development. This may be mainly due to the resource-intensive nature of examining and coding twice the amount of infant attachment patterns in studies of this nature (i.e., attachment to both mother and father), the limited number of studies that did assess infant attachment networks have been limited in sample size (around 30-100 infants). As a result, studies have thus far produced mixed findings. This has contributed to theoretical inconsistencies regarding whether the configuration of infants' attachment patterns to their mothers and fathers predicts future developmental outcomes better than the unique effect of attachment patterns with either parent alone (Dagan \& Sagi-Schwartz, 2018; Dagan \& Sagi-Schwartz, in press) .

Research on the joint influence of attachment patterns to both parents has been a challenge because it requires an assessment of a very large number of triads (infant, mother, and father) in order to obtain a large enough sample size of 4 different configuration groups: (a) insecure with both parents $(\mathrm{I}-\mathrm{I})$; (b) secure with mother, insecure with father $\left(\mathrm{S}_{\mathrm{M}^{-}} \mathrm{I}_{\mathrm{F}}\right)$; (c) insecure with mother, secure with father $\left(\mathrm{I}_{\mathrm{M}}-\mathrm{S}_{\mathrm{F}}\right)$; and (d) secure with both parents (S-S). For example, Dagan and Sagi-Schwartz (2018) noted that ensuring an adequately powered four-group sample that meets the minimum quota for the smallest probable attachment configuration group (infants who are insecurely attached to both parents; approximately $15 \%$ of the children) requires assessing at least 440 infants for attachment patterns with both parents. Administering behavioral attachment assessments for 440 infants with both parents, as well as developmental outcome assessments across time, would be both an extremely complex and laborious endeavor. The most feasible step towards answering the question of whether the configuration of infants' attachment patterns to their mothers and fathers predicts future developmental outcomes better than previously studied in the field would be the aggregation of data currently already available.

Although a traditional meta-analysis is most often used to quantify the results accumulated via multiple studies, such a meta-analytic procedure cannot reliably answer the research question at hand due to two main reasons. First, for assessing the predictive power of infant attachment network on later developmental outcomes, a traditional meta-analysis would be bound by the selections made in primary studies for reporting outcomes. This would limit comparison and aggregation of outcome constructs (e.g., cognitive, socioemotional, and psychopathological symptoms/behaviors outcomes). Second, because papers contain only sample aggregates of moderating factors (e.g., parental age, socioeconomic status), studying moderator effects in a traditional meta-analysis would disregard any within-sample variation, leading to biased moderator effects (Lau, loannidis, \& Schmid, 1998; Stewart \& Tierney, 2002). Relatedly, cross-level interactions between participant characteristics and study characteristics could not be studied. 
The most powerful and feasible way to meaningfully aggregate findings regarding infant attachment network to mother and father is via an individual participant data (IPD) meta-analysis (Verhage et al., in press). IPD meta-analysis involves accumulating and aggregating raw participant data from relevant studies (Riley, Lambert, \& Abo-Zaid, 2010). In the case of attachment network assessment, IPD meta-analytic procedures would overcome some of the limitations of traditional metaanalysis in two main ways. First, gathering raw data will enable us to standardize and harmonize outcome data from multiple outcome measures used in the original studies (some of which may have not been reported) to arrive at a more comprehensive set of outcomes constructs of interest. Second, IPD meta-analysis will allow for examination of moderator effects to test the boundaries of the investigated models, and arrive at more credible findings (Ioannidis, 2017); these will be available due to the use of (a) individual-level data which takes into account within-sample variability, and (b) the use of more data than is reported in manuscripts, which increases power for the main and moderator tests.

Bringing together individual participant data from multiple studies that assessed infant/child attachment patterns to both parents and developmental outcomes will also enable the consortium to reconfigure previously collected data according to a priori models (e.g., create groups such as S-S and I-I) that may or may not have been considered in the original studies. The number of participants aggregated via IPD - potentially 10 times the amount of data reported in published attachment network models thus far (see Appendix B for a provisional list of eligible studies)- will significantly increase the analytic power to detect effects of attachment network on developmental outcomes.

\section{Research Questions}

\section{Hypothesis-testing}

As described above, in the largely US and European nuclear families that have been considered in the attachment literature to date, infants and children may form two attachment relationships: one with mother and one with father. This results in one of four attachment configurations: (a) insecure with both parents (I-I); (b) secure with mother, insecure with father $\left(\mathrm{S}_{\mathrm{M}}-\mathrm{I}_{\mathrm{F}}\right)$; (c) insecure with mother, secure with father $\left(\mathrm{I}_{\mathrm{M}}-\mathrm{S}_{\mathrm{F}}\right)$; and $(\mathrm{d})$ secure with both parents $(\mathrm{S}-\mathrm{S})$. Accordingly, we raise two research questions that may be answered by testing competing hypotheses (Figure 1; see Appendix E).

Research Question 1: Does the number of secure attachments matter in predicting developmental outcomes, or is one secure attachment sufficient for optimal development? The Additive versus Buffering Hypotheses

Some findings support the Additive Hypothesis (Dagan \& Sagi-Schwartz, 2018), which predicts a linear "dose-response" association between the number of secure attachment patterns and developmental outcomes. That is, children who are securely attached to both parents will show the best outcomes, followed by children who are securely attached to only one parent, whereas children who are insecurely attached to both parents will have the poorest outcomes. In contrast, other studies showed that infants who were secure with only one parent showed comparable outcomes to infants who were securely attached to both parents, but had better outcomes than those who were insecurely attached to both parents. Such findings are consistent with the Buffering Hypothesis (Dagan \& Sagi-Schwartz, 2018), according to which an early secure attachment to one parent is sufficient to offset the risk effects of an insecure attachment to the other, and there is no advantage to having a secure attachment to both parents.

In line with attachment theory and meta-analytic results regarding the intended outcome testing (see under Harmonization of developmental outcome measures below), we hypothesize that the predictive effect of multiple attachment relationships on developmental outcomes of interest 
is consistent with the Additive Model. That is, children with secure attachment to both parents will show better developmental outcomes than children with secure attachment to only one parent, and the latter will show better developmental outcomes than children who are insecurely attached to both parents. If the null hypothesis will fail to be rejected, the Buffering Hypothesis will be tested as an alternative hypothesis, based on preformulated auxiliary hypotheses put forward by Dagan \& SagiSchwartz (2018).

Research Question 2: Does one parent contribute more than the other to developmental outcomes, or do they matter equally? The Hierarchical versus Horizontal Hypotheses

According to the Hierarchical Hypothesis (Bowlby, 1969; Bretherton, 1985; Van IJzendoorn et al., 1992), one parent influences the developmental outcomes of the child more than the other parent. This would result in one of two possible developmental trajectories: infants securely attached to the mother and insecurely attached the father will show better developmental outcomes than those securely attached to the father but insecurely attached to the mother, or vice versa. In contrast, the Horizontal Hypothesis (Dagan \& Sagi-Schwartz, 2018) predicts that infants with a secure attachment to only the mother exhibit similar developmental outcomes to those who form a secure attachment only to the father.

Assuming that mothers are on average more involved in time and across domains with child rearing than fathers (e.g., Parker \& Wang, 2013), it is plausible that the quality of attachment with mother would affect outcome more strongly than the quality of child-father attachment. In line with attachment theory and meta-analytic results regarding the intended outcome testing, we hypothesize that developmental outcomes of interest will be predicted in accordance with the Hierarchical Model, with child-mother attachment influencing more strongly on the developmental outcome of interest than child-father attachment. That is, children with secure attachment only to mother will show better developmental outcomes than children with secure attachment only to only father. If the null hypothesis will fail to be rejected, the Horizontal Hypothesis will be tested as an alternative hypothesis, based on preformulated auxiliary hypotheses put forward by Dagan \& Sagi-Schwartz (2018).

Research Question 3: Which integrative model best predicts developmental outcomes?

Overall, these research questions and sets of competing hypotheses (Additive vs. Buffering and Hierarchical vs. Horizontal) combine into four mutually exclusive explanatory models: (a) AdditiveHierarchical, (b) Additive-Horizontal, (c) Buffering-Hierarchical, and (d) Buffering-Horizontal. Table 1 (see Appendix F) depicts the model-based predictions, including the relations between the different attachment configurations within each model.

Stemming from Research Questions 1 and 2 above, we hypothesize that developmental outcomes of interest will be predicted in accordance with the Additive-Hierarchical Model. That is, children who are securely attached to both parents will show the best outcomes compared to all other groups, followed by children who are securely attached only to the mother, and then those who are securely attached only to the father. Children with insecure attachment to both parents will exhibit the worst outcomes of all four groups.

\section{Exploratory research questions}

(a) Does attachment insecurity with one parent lead to better developmental outcomes in high risk populations? Based on findings from existing published research on infant attachment networks, as well as meta-analyses finding that secure attachment predicts better socioemotional outcomes than insecure attachment (e.g., Groh et. al., 2014; Fearon, 2014), all four of the models (Additive-Hierarchical, Additive-Horizontal, Buffering-Hierarchical, and Buffering-Horizontal; see Table 1 below) predict that infants who are securely attached to one 
parent (S-I) will fare no better than infants who are securely attached to both parents (S-S). While this pattern is most plausible based on theory and evidence to date, other theorizing leads to the possibility that in some rearing environments, having one insecure attachment within the family may actually allow infants to better adapt to high-risk ecological contexts than infants who are securely attached to both parents. This may be the case, for example, in contexts that are characterized by high competition for resources and low trust (Ellis, Bianchi, Griskevicius, \& Frankenhuis, 2017). For example, insecurely attached children tend to better recall negative events than secure children (Belsky, Spritz, \& Crnic, 1996); as such, they may benefit from either detection or avoidance of negative events in their high risk environment in the future. This adaptive attentional capacity may, in turn, attenuate otherwise excessive psychopathological symptoms that tend to arise as a result of such harsh environments. Accordingly, we will explore whether infants who are securely attached to only one parent- the S-I group- exhibit better (according to the prevailing hypothesis in the field) developmental outcomes in high-stress, low resource contexts than their counterparts who are securely attached to both parents (i.e., the S-S group). For example, it might be the case that in high risk

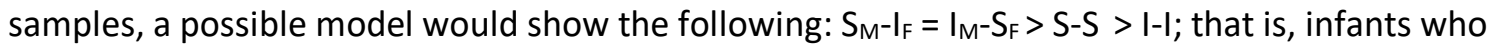
are securely attached to either parent will show non significantly different developmental outcomes but both groups will fare better than the S-S group.

(b) Moderators for Research Question 1. Given that risk conditions have been found to moderate the link between infant attachment patterns and multiple developmental outcomes (e.g., Groh et al., 2014), we will examine whether parental risk status moderates the link between the number of secure attachments and each of the developmental outcomes. For example, we would expect that having two secure attachment relationships may buffer the deleterious effect of high risk environmental conditions (e.g., low SES, parental psychopathology) on the developing child more effectively than having only one secure attachment relationship; the buffering effect of secure attachment with one parent on the potential deleterious effects of insecure attachment with the other parent, in contrast, may show insignificant low-risk environmental conditions, where little stress is experienced.Moreover, some studies found that longer time intervals between assessment of attachment patterns and developmental outcomes led to a smaller effect size of the link between them the two (e.g., Colonnesi et al., 2011; Madigan et al., 2013; but see Groh et al., 2014, for contrary meta-analytic evidence). Accordingly, we will test whether the time gap between the most recent of the two attachment network assessments and development outcomes moderates the link between early attachment network and each of the developmental outcomes of interest. We expect that the larger the time gap, the smaller the effect size between the attachment network and developmental outcomes.

(c) Moderators for Research Question 2. Parents may differ with respect to the level of involvement in child rearing (Bakermans-Kranenburg, Lotz, \& Dijk, 2019; Brown, McBride, Bost, \& Shin, 2011; Renk et al., 2003). Accordingly, we will test for moderation effects of relative parental involvement. For example, we would expect that in triads where mothers are more involved in child rearing than fathers, the Hierarchical hypothesis, but not the Horizontal hypothesis, will be corroborated. In such cases, it is reasonable to predict that interacting more with the developing child will make mothers more influential than fathers. 


\section{General methods}

\section{Objectives}

The main aim of the project is to add to our understanding of how the joint effect of early attachment to both mothers and fathers may influence later developmental outcomes. The question at hand is as follows: What role do two infant/child-parent attachment relationships jointly play in children's developmental outcomes? The few studies conducted to date on the integration of infant-mother and infant-father attachment patterns focused exclusively on dichotomous secure/insecure classifications (e.g., (Sagi-Schwartz \& Aviezer, 2005; Suess, Grossmann, \& Sroufe, 1992; van IJzendoorn, Sagi, \& Lambermon, 1992; Verschueren \& Marcoen, 1999). However, in this IPD meta-analysis we will further examine the infant attachment network with respect to attachment disorganization, given the significance of attachment disorganization in predicting key developmental outcomes (e.g., Fearon et al., 2010; Lyons-Ruth, Pechtel, Yoon, Anderson, \& Teicher, 2016; Van IJzendoorn, Schuengel, \& BakermansKranenburg, 1999 ). The aforementioned research question will thus be articulated, and accordingly empirically assessed in terms of two attachment variables: (1) the status of infant security of attachment to each parent (secure versus insecure); and (2) the status of infant disorganization to each parent (organized versus disorganized).

We choose to assess attachment networks based on the categorical classification of infant attachment security since it has been the most widely used approach, and thus we anticipate maximum available sample size collecting categorical data. However, the argument has been made that there may be a potential advantage of assessing attachment security via a dimensional approach (e.g., Fraley \& Spieker, 2003; Groh et al., 2019; Richters, Waters, \& Vaughn, 1988). Although we anticipate a significant reduction in sample size, we will attempt to collect dimensional data for the purpose of sensitivity analyses (see Sensitivity analyses sub-section below).

\section{Harmonization of developmental outcome measures}

One of attachment theory's main assumptions is that early infant-parent relationship experiences play a crucial role in promoting positive social and emotional adaptation across the life course (Bowlby, 1969; Carlson \& Sroufe, 1995). The mechanism underlying this assumption states that early infant experiences with caregivers at times of need feed into expectations about social relationships (Bowlby, 1973; Bretherton \& Munholland, 2008). Specifically, these expectations have been thought to shape the individuals interpersonal behaviors (Bretherton, 1985, 1991, 1992; Sroufe, Egeland, Carlson, \& Collins, 2005; Sroufe \& Waters, 1977) and mental health (Groh et al., 2014). In line with this theoretical assumption, meta-analyses confirmed that outcome constructs known to be predicted by early infant attachment patterns as assessed via observation methods are (a) social competence (Groh et al., 2014; Schneider, Atkinson, \& Tardif, 2001) and two dimensions of developmental psychopathology, namely (b) internalizing behaviors and (c) externalizing behaviors (Colonnesi et al., 2011; Fearon, Bakermans-Kranenburg, van IJzendoorn, Lapsley, \& Roisman, 2010; Groh, Roisman, van IJzendoorn, Bakermans-Kranenburg, \& Fearon, 2012; Madigan, Atkinson, Laurin, \& Benoit, 2013).

Meta-analyses that assessed associations between infant attachment and other developmental outcome domains have been published as well. These meta-analyses will be used to assess the feasibility for testing additional theory driven hypotheses, for which we will collect the following outcome constructs as well. Sufficient data needs to be available to achieve a priori set power of 0.80 regarding the following outcome domains: (d) language competence (Van IJzendoorn, Dijkstra, \& Bus, 1995); (e) emotional understanding (Cooke et al., 2016); (f) emotional regulation, including positive and negative affectivity (Cook et al., 2018); (g) effortful control (Pallini et al., 2018), and (h) self-regulation 
(Pallini et al., 2018). The outcome data will be harmonized based on either independent informant (i.e., non-mother and son-father informant, such as teachers), or when independent informants are not available, on the average scores of mother and father reports.

Outcome constructs may have been operationalized with a range of measures. A protocol for harmonizing outcome measures will be developed jointly for IPD meta-analyses within the Collaboration for Attachment Research Synthesis (CARS). This harmonization protocol will be developed in particular jointly with the ongoing CAPIS project (Collaboration for Attachment and Parenting Intervention Synthesis; Van IJzendoorn, Reisz, Reijman, Duschinsky, Schuengel, et al.).

\section{Eligibility criteria}

Studies must have:

- Assessed infant or child attachment patterns with both mothers and fathers using an observational tool. In cases where the time gap between attachment observational measures is unknown, analyses without these samples will be run as part of sensitivity testing.

- Assessed either concurrent or later developmental outcomes.

- Used an attachment behavioral coding measure for caregiver-child attachment, coded by observers (i.e., excluding parent-report, parent-observation, self-report, self-observation, and projective measures)

\section{$\underline{\text { Identification of studies }}$}

Studies for the current project (see Appendix B) were drawn based on the eligibility criteria from the Child Attachment Studies Catalogue and Data Exchange (CASCADE), the Determinants of Child Development Lab in the Department of Psychology, University of Calgary, with the permission and supervision of the lab director, Dr. Sheri Madigan. CASCADE is a catalogue of all research studies until 2017) that have assessed infant and child attachment. Search for CASCADE using the search terms (see Appendix A) was conducted the following databases: Medline, EMBASE, PsychINFO, and Web of

\section{Science.}

\section{Data collection}

Data on the main study variables, participant characteristics, and study characteristics will be sought for all participants.

\section{Caregiver-child attachment:}

- Type of measure

- In case of multiple infant attachment assessments with the same parent, preference will be given to SSP classifications, because this measure has been most widely used and reported in the field and previous IPD meta-analysis that examined infant attachment (Verhage et al., 2018). For the purpose of constructing the different configurations of infant attachment networks to mothers and fathers, attachment classifications will be grouped into (a) secure and insecure (comprising of avoidant, resistant, and cannot-classify attachment classifications, with or without primary disorganized classification); and (b) organized (secure and insecure attachment classifications which were not assigned with a primary disorganized classification) and disorganized .

- Consistent with previous research (Lehman, Denham, Moser, \& Reeves, 1992) and IPD metaanalysis that examined infant attachment (Verhage et al., 2018), Attachment Q-Sort (AQS; Waters \& Deane, 1985) scores will be categorized as secure or insecure based on a cutoff score 
of .40; scores above the cutoff will be categorized as secure, and scores equal to or below the cutoff will be classified as insecure.

If Strange Situation Procedure (including SSP-modified version, and the Preschool Assessment of Attachment [PAA]):

- SSP forced main classification

- SSP forced sub-classification

- SSP four-way main classification (not applicable to the PAA)

- SSP four-way sub-classification (not applicable to the PAA)

- SSP D-score (not applicable to the PAA)

- SSP Behavior rating scales (Proximity seeking, Contact maintenance, Resistance, Avoidance)

If Attachment Q-Sort:

- AQS continuous score

If Preschool Attachment Assessment:

- PAA main classification

- PAA sub-classification

If Main-Cassidy classification system:

- Main-Cassidy system forced main classification

- Main-Cassidy system forced sub-classification

- Main-Cassidy system four-way main classification

- Main-Cassidy system four-way sub-classification

- Main-Cassidy system D-score

- Main-Cassidy system scales

Characteristics of child and caregivers:

- Age

- Social support for each caregiver

- Relationship status with respect to the other caregiver (e.g., married, divorced)

- Current relationship status

- Education level

- Income

- Occupation

- Ethnicity

- Clinical status

- Risk status (this may vary depending on the sample; e.g., adolescence parents, low SES, poverty)

- Type of caregiver (biological parent, foster parent, adoptive parent)

- Gender parent

- Gender child

- Child identifier (anonymized)

- Parental involvement

A suggested coding format for these data is provided (see attached SPSS sheet to this project). It would be helpful if individual researchers provided their data in the suggested format, but it is not essential to do so. Data will be accepted in any format that is most convenient for the researchers. Any data supplied electronically should be encrypted or sent through a secure ftp server. A final copy of the data from each study will be sent back to the researchers for verification. 
Main analyses

In the following analyses, all studies will be analyzed in a single step by using a multilevel structure to account for the variance within studies, with developmental outcomes being the dependent variables and attachment networks being the predictors.

\section{Analysis 1: Testing the Additive versus Buffering Hypotheses (Research Question 1)}

We will conduct a series of one-way analysis of variance (ANOVAs), where each developmental outcome will be the dependent variable, and attachment network (secure with both parents [S-S], secure with only one parent [S-I], and insecure with both parents [I-I]) will be the independent between-subjects factors. Planned contrasts (polynomial, quadratic) will be used to test the buffering hypothesis first (to establish whether having any secure attachment relationship is associated with more adaptive outcomes (contrasts "no secure attachments" [-2], "one secure attachment" [+1], "two secure attachments" [+1]), followed by the additive hypothesis that tests whether having two secure attachment relationships is associated with more adaptive outcomes than having one (contrasts "no secure attachments" [0], "one secure attachment" [-1], "two secure attachments [+1]) Similar contrasts will be tested for disorganized attachment.

For example, if I-I infants will show significantly more internalizing symptoms than both S-S and S-I infants, but the latter two groups will not show significantly different outcome means, it will indicate that being secure with at least one parent is beneficial compared with being insecure with both; accordingly, the Buffering hypothesis will be corroborated. Alternatively, if I-I infants will show significantly more internalizing symptoms than both S-S and S-I infants, and S-I infants will show significantly more internalizing symptoms than the S-S infant group, it will indicate that the more secure attachment an infant has, the better the outcome; accordingly, the Additive hypothesis will be corroborated.

\section{Analysis 2: Testing the Hierarchical versus Horizontal Hypotheses (Research Question 2)}

We will conduct a series of one-way analysis of variance (ANOVAs), where each developmental outcome will be the dependent variable, and attachment network (secure only with mother $\left[S_{m}-I_{f}\right]$, secure with only with father $\left[\mathrm{I}_{\mathrm{m}}-\mathrm{S}_{\mathrm{f}}\right]$ ) will be the independent between-subjects factors. Given that only two groups will be compared, no planned contrasts will be conducted.

\section{Analysis 3: Comparing the four attachment network models (Research Question 3)}

We will conduct a series of one-way analysis of variance (ANOVAs), where each developmental outcome will be the dependent variable, and attachment network (secure with both parents [S-S], secure with only mother $\left[S_{M}-I_{F}\right]$, secure with only father $\left[I_{M}-S_{F}\right]$, and insecure with both parents $\left.[I-I]\right)$ will be the independent variable. Planned contrasts (polynomial, quadratic) will be used to test whether infants with two insecure attachments fare worse than infants with at least one secure attachment (contrasts "no secure attachments" [-3], "one secure attachment with mother" [+1], "one secure attachment with father" [+1], "two secure attachments" [+1]). Then, we will contrast the S-S group (+2) with both of the single secure attachment groups (Sm-If [-1], Im-Sf [-1]) to test whether these groups are organized according to the buffering hypothesis (insignificant planned comparison analysis) or additive hypothesis (significant planned comparison analysis, with S-S group showing outcome average representing better outcome than the other two infant groups). Then, we will directly contrast Sm-If $(-1)$ and Im-Sf $(+1)$ groups to test whether these groups are organized according to the horizontal hypothesis (insignificant planned contrasts analysis), or hierarchical hypothesis (significant planned contrast analysis, with parent 
dominance decided based on the group outcome average). In cases where the model predicts an absence of meaningful effect between two groups (e.g., as in the case of the Buffering-Horizontal hypothesis, where $S-S=S_{M}-I_{F}=I_{M}-S_{F}$ ), equivalence tests will be performed to assess statistical equivalence (on top of the statistical difference from zero; Lakens, 2017). Based on the pattern of planned contrast results, we will be able to either corroborate or falsify all four models proposed in Appendix C.

For example, if I-I infants will show significantly more internalizing symptoms than all other 3 infant groups (i.e., $S-S, S_{M}-I_{F}, I_{M}-S_{F}$ ), and all 3 other infant groups will show statistical equivalence, we may conclude that being secure with at least one parent is beneficial compared with being insecure with both, and that there is no primary caregiver with which secure attachment is more important than the other with regards to this specific outcome; accordingly, the Buffering-Horizontal hypothesis will be corroborated.

\section{Sensitivity analysis}

To assess the robustness of findings, we will conduct several sensitivity analyses.

(1) Given that no research has robustly established a minimum interval time below which a spillover effect from one SSP assessment to another may occur when administered to the same infant, all available SSP data will be requested and analyzed according to the research questions posed above. We will conduct a Regions of Significance testing (RoS; e.g., Roisman, Newman, Fraley, Haltigan, Groh, \& Haydon, 2012) to assess at what level of the moderator (i.e., continuous measure of the number of days between SSP assessment)- if any- does the link between attachment network and the developmental outcome at hand becomes significant.

(2) We will test our findings against competing analyses that are based on other assessment methodologies: (a) Comparing outcomes based on individual differences in attachment networks derived at via traditional categorical attachment classifications (i.e., secure/insecure) versus classifications which are arrived at by computing continuous scores (for SSP dimensions, see Fraley, \& Spieker, 2003; Richters, Waters, \& Vaughn, 1988. For AQS cut-off scores, see Verhage et al., 2018); (b) Comparing the harmonized outcome data we chose to test in our primary analyses (see "Harmonization of developmental outcome measures" above) versus harmonized outcome data based on other informats (e.g., mother report alone, father report alone, and self-report).

(3) We will perform a sensitivity analysis for differential effects between complete and imputed data.

(4) We will conduct post-hoc sensitivity power analysis based on the number of participants collected from the different studies (see Appendix B), and assuming a power $=.80$ and a $p=.05$. This will allow us to assess the smallest effect that we could detect with high probability given the number of collected participants (i.e., minimal detectable effect; MDE).

\section{Project coordination}

The day-to-day conduct of these meta-analyses will be carried out by the project coordination team at both Stony Brook University and Vrije Universiteit Amsterdam. 


\section{Timetable}

November2019: Write to study authors to ask for collaboration

Spring 2020- Spring 2021: Check and verify incoming data, build database

Spring/Summer 2021: Data analyses

\section{Privacy policy}

Data should be sent without any identifying information on participants. Data sent through our FTP server will be encrypted as soon as it is uploaded. Data sent through regular mail or fax will be stored in a closed cabinet. The checking and combining of the data will be done at Vrije Universiteit and data files will be password-protected. Data analysis will take place at Vrije Universiteit or remotely over a secure connection on the protected server of Vrije Universiteit by a core member of the project from his or her research institute, based on a data sharing agreement between both institutes. Data will not be used, circulated, or distributed in any way that allows access to individual study data, without first seeking permission of the PI of the data set. Only core members of the research team may have access to the ensemble data. Individual datasets/studies will not be retracable to the original researchers in the final combined dataset.

\section{Publication policy}

After identification of eligible studies, study authors will be contacted and asked to participate in the Collaboration for Attachment to Multiple Parents and Outcomes Synthesis (CAMPOS). By agreeing to participate, authors commit to providing data on their participants for use in the project. Participating authors will become members of the collaborative group and all results from the meta-analyses will be presented in the group's name, and will be invited to contribute as named or group author to the writing of manuscripts based on the project. Participating authors will also be invited to a collaborators meeting in which the results will be presented.

All results of these meta-analyses will be presented in the CAMPOS group name, comprising of all authors who contributed data for the meta-analyses, the International Advisory Group, and the Project Coordination Group. Initial results will be presented in a closed meeting of CAMPOS. All contributors have the opportunity to comment on the results and provide feedback during this meeting, after which abstracts will be written to be presented at international conferences. Several manuscripts containing the research questions will be drafted, which will be circulated to each CAMPOS members for comments. Manuscripts will be submitted for publication to peer-reviewed journals. 


\section{Appendix A - Search term}

strange situation*; (secure* or resist* or avoid* or disorganiz ${ }^{*}$ ); ("attachment q sort" or "attachment q-sort" or "Cassidy and Marvin" or "preschool assessment of attachment" or "Main-Cassidy" or "preschool attachment assessment" or "school age attachment")." 
Appendix B - Provisional list of eligible studies

\begin{tabular}{|c|c|c|}
\hline First author name (Year) & Triad $N$ & $\begin{array}{c}\text { Infant/child } \\
\text { Attachment } \\
\text { measure }\end{array}$ \\
\hline Abrams, Kelley Yost (2006) & 25 & SSP \\
\hline Abrams, Kelley Yost (2000) & 25 & SSP \\
\hline Arnott, Bronia (2007) & 15 & SSP \\
\hline Aviezer, Ora (2002) & 66 & SSP \\
\hline Bar-Haim, Yair (2002) & 64 & SSP \\
\hline Belsky, Jay (1984) & 61 & SSP \\
\hline Belsky, Jay (1988) & 130 & SSP \\
\hline Belsky, Jay (1987) & 184 & SSP \\
\hline Belsky, Jay (1996) & 125 & SSP \\
\hline Boldt, Lea (2017) & 102 & SSP \\
\hline Boldt, Lea (2016) & 99 & SSP \\
\hline Boldt, Lea (2014) & 100 & SSP \\
\hline Braungart-Rieker, Julia M. (2001) & 86 & SSP \\
\hline Braungart-Rieker, Julia M. (1999) & 77 & SSP \\
\hline Braungart-Rieker, Julia M. (2014) & 114 & SSP \\
\hline Brock, Rebecca L. (2014) & 62 & AQS \\
\hline Brown, Geoffrey L. (2010) & 62 & SSP \\
\hline Bureau, Jean-François (2014) & 107 & SSP-M \\
\hline Bus, Adriana G. (1997) & 100 & SSP \\
\hline Caldera, Yvonne M. (2006) & 60 & AQS \\
\hline Chase-Lansdale, P. Lindsay (1987) & 97 & SSP \\
\hline Colonnesi, Cristina (2013) & 20 & AQS \\
\hline Cox, Martha J. (1992) & 33 & SSP \\
\hline Coyl, Diane D. (2010) & 235 & $\mathrm{AQS}$ \\
\hline Edwards, Ellen P. (2004) & 208 & SSP \\
\hline Fonagy, Peter (1991) & 100 & SSP \\
\hline Freitag, Milam K. (1996) & 40 & SSP \\
\hline Frodi, Ann (1983) & 51 & SSP \\
\hline Frosch, Cynthia A. (2001) & 131 & SSP \\
\hline Fuertes, Marina (2016) & 82 & SSP-M \\
\hline Garwood, Molly Murphy (1998) & 105 & SSP \\
\hline George, Melissa Renee Ward (2010) & 235 & SSP-M \\
\hline Goldberg, Susan (1984) & 75 & SSP \\
\hline Goossens, Frits A. (1990) & 75 & SSP \\
\hline Grossman, Karin (2002) & 49 & SSP \\
\hline Grossman, Klaus (1981) & 46 & SSP \\
\hline Heidt-Kozisek, Elizabeth (1997) & 30 & SSP \\
\hline $\begin{array}{l}\text { Hinshaw-Fuselier, Sarah Seymour } \\
\text { (2004) }\end{array}$ & 125 & SSP \\
\hline Kazura, Kerry (2000) & 27 & SSP \\
\hline Kennedy, Mark (2015) & 30 & AQS \\
\hline
\end{tabular}




\begin{tabular}{|c|c|c|}
\hline Kim, Sanghag (2014) & 102 & SSP \\
\hline Kochanska, Grazyna (2012) & 102 & SSP \\
\hline Kochanska, Grazyna (2005) & 101 & SSP \\
\hline Kochanska (2013) & 101 & SSP \\
\hline Kochanska, Grazyna (2010) & 101 & SSP \\
\hline Lamb, Michael E. (1978) & 32 & SSP \\
\hline Lamb, Michael E. (1982) & 51 & SSP \\
\hline Laurent, Heidemarie K. (2008) & 80 & PAA \\
\hline Lickenbrock, Diane M. (2015) & 117 & SSP \\
\hline Lickenbrock, Diane M. (2013) & 106 & SSP \\
\hline Lickenbrock, Diane M. (2010) & 135 & SSP \\
\hline Lindsey, Eric W. (2009) & 80 & SSP \\
\hline Lindsey, Eric W. (2015) & 86 & SSP \\
\hline Lionetti, Francesca (2014) & 30 & SSP \\
\hline Lundy, Brenda L. (2002) & 15 & AQS \\
\hline Madigan, Sheri (2011) & 31 & SSP \\
\hline Main, Mary (1988) & 40 & SSP \\
\hline Main, Mary (1985) & 40 & SSP \\
\hline Main, Mary (1981) & 61 & SSP \\
\hline McElwain, Nancy L. (2004) & 62 & SSP \\
\hline McElwain, Nancy L. (1999) & 53 & SSP \\
\hline Moilanen, Irma (2000) & 60 & SSP \\
\hline Moilanen, Irma (2000) & 30 & SSP \\
\hline Monteiro, Ligia (2008) & 56 & AQS \\
\hline Monteiro, Ligia (2010) & 44 & AQS \\
\hline Moore, Ginger A. (1996) & 136 & SSP \\
\hline Notaro, Paul C. (1999) & 62 & SSP \\
\hline Oppenheim, David (1988) & 59 & SSP \\
\hline Owen, Margaret Tresch (1981) & 132 & SSP \\
\hline Owen, Margaret Tresch (1984) & 59 & SSP \\
\hline Owen, Margaret Tresch (1997) & 33 & SSP \\
\hline Pipp, Sandra (1993) & 30 & SSP \\
\hline Planalp, Elizabeth M. (2013) & 115 & SSP \\
\hline Sagi, Abraham (1986) & 86 & SSP \\
\hline Sagi, Abraham (1985) & 86 & SSP \\
\hline Schneider Rosen, Karen (1993) & 62 & SSP \\
\hline Schneider Rosen, Karen (1999) & 41 & SSP, AQS \\
\hline Schoppe-Sullivan, Sarah (2006) & 87 & SSP \\
\hline Solomon, Judith (1999) & $?$ & SSP \\
\hline Steele, Howard (1996) & 100 & SSP \\
\hline Steele, Howard (1999) & 63 & SSP \\
\hline Steele, Howard (2008) & 63 & SSP \\
\hline Suess, G. J. (1992) & 39 & SSP \\
\hline Tirkkonen, Tiina (2016) & 54 & PAA \\
\hline Tluczek, Audrey (2015) & 118 & AQS \\
\hline Umemura, Tomo (2013) & 102 & SSP \\
\hline
\end{tabular}


van Ee, E. (2016)

van IJzendoorn, Marinus H. (1992)

$\begin{array}{cc}68 & \text { SSP } \\ 80 & \text { SSP } \\ 86 & \text { SSP } \\ 35 & \text { AQS } \\ 30 & \text { SSP } \\ 45 & \text { SSP } \\ 224 & \text { AQS } \\ 70 & \text { AQS } \\ 62 & \text { SSP } \\ 67 & \text { SSP } \\ 73 & \text { SSP, AQS } \\ 73 & \text { SSP, AQS } \\ 46 & \text { SSP }\end{array}$

van IJzendoorn, Marinus H. (1992)

Verissimo, Manuela (2011)

Volling, Brenda L. (1992)

Volling, Brenda L. (2001)

Volling, Brenda L. (2014)

Wille, Diane E. (1998)

Wong, Maria (2009)

Youngblade, Lise M. (1995)

Youngblade, Lise M. (1993)

Youngblade, Lise M. (1992)

Zentall, Shannon R.(2012) 


\section{Appendix C: Figure 1}

Figure 1 (from on Dagan \& Sagi-Schwartz, 2018). Four competing hypotheses, ordered according to the issue they address.

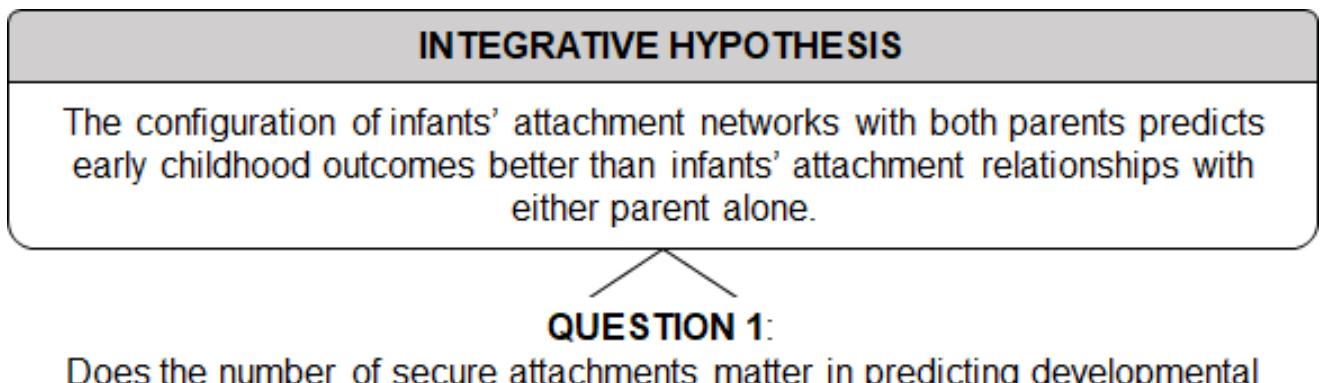

Does the number of secure attachments matter in predicting developmental outcomes?

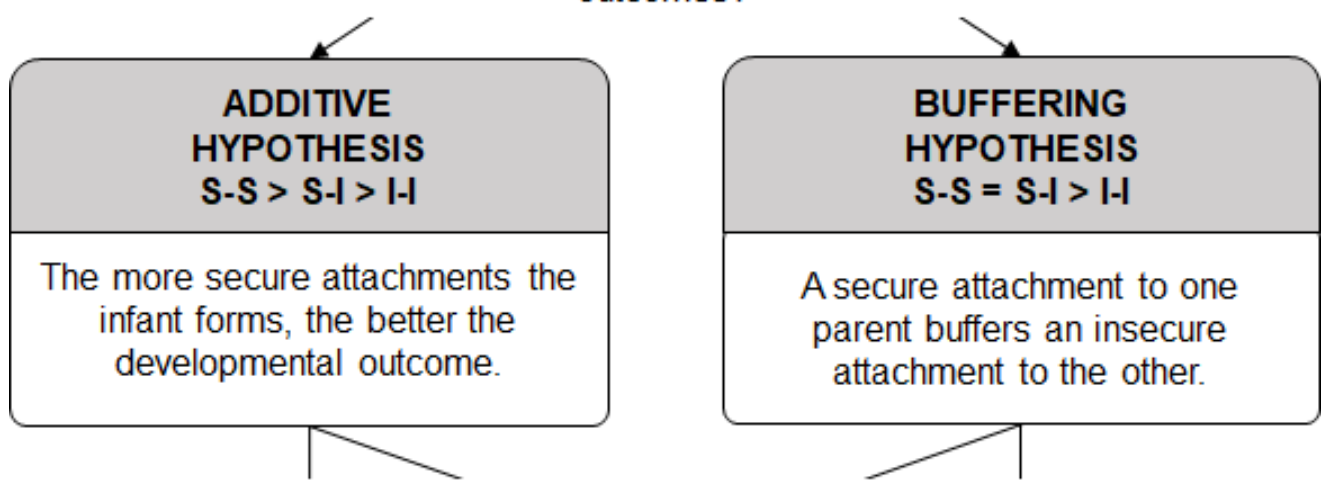

\section{QUESTION 2 .}

Does one parent contribute more than the other to developmental outcomes?
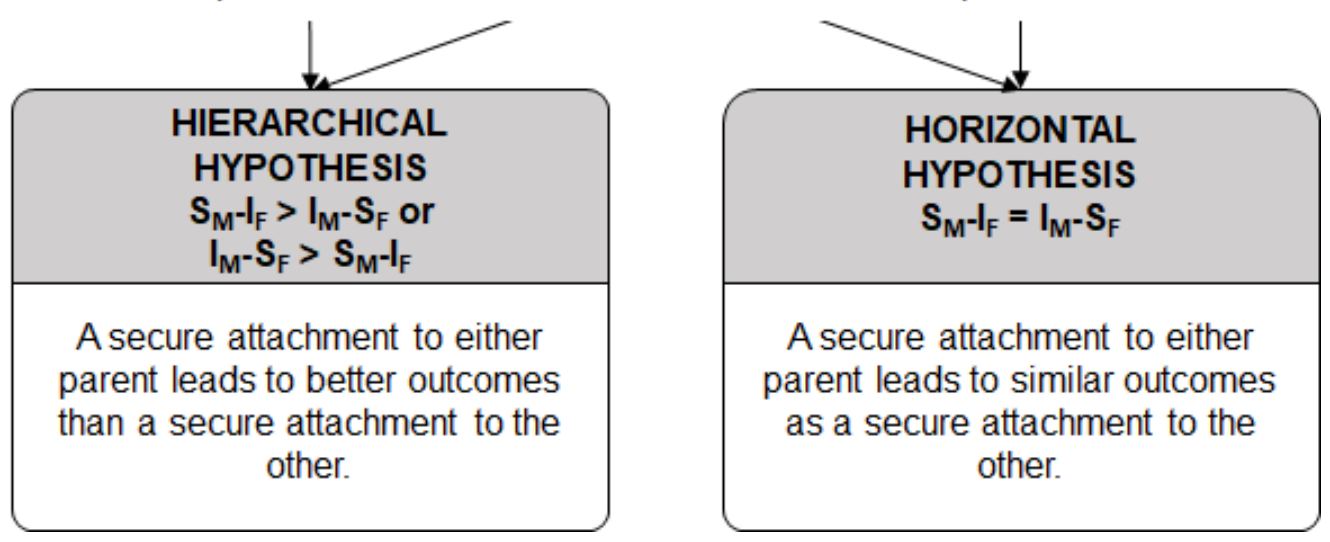

Note. S-S = secure with mother and father; I-I = insecure with mother and father; $\mathrm{SM}=$ secure with mother; $S F=$ secure with father; IM = insecure with mother; IF = insecure with father. 


\section{Appendix D: Table 1}

Table 1 (from on Dagan \& Sagi-Schwartz, 2018). Model-Based Outcome Predictions.

\begin{tabular}{|c|c|c|}
\hline Integrative Model & Prediction* & Brief Description \\
\hline (a) Additive-Hierarchical & $\begin{array}{l}\mathrm{S}-\mathrm{S}>\mathrm{S}_{\mathrm{M}}-\mathrm{IF}_{\mathrm{F}}>\mathrm{IM}_{\mathrm{M}}-\mathrm{S}_{\mathrm{F}}>\mathrm{I}-\mathrm{I} \\
\quad \mathrm{OR} \\
\mathrm{S}-\mathrm{S}>\mathrm{IM}_{\mathrm{M}}-\mathrm{S}_{\mathrm{F}}>\mathrm{SM}_{\mathrm{M}}-\mathrm{I}_{\mathrm{F}}>\mathrm{I}-\mathrm{I}\end{array}$ & $\begin{array}{l}\text { Secure attachment to only one parent (but not the other) leads to better outcomes than insecure } \\
\text { attachment to both parents, but poorer outcomes than secure attachment to both parents. }\end{array}$ \\
\hline (b) Additive-Horizontal & $\mathrm{S}-\mathrm{S}>\mathrm{S}_{\mathrm{M}}-\mathrm{I}_{\mathrm{F}}=\mathrm{IM}_{\mathrm{M}}-\mathrm{S}_{\mathrm{F}}>\mathrm{I}-\mathrm{I}$ & $\begin{array}{l}\text { Secure attachment to either parent (but not the other) leads to better outcomes than insecure } \\
\text { attachment to both parents, but poorer outcomes than secure attachment to both parents. }\end{array}$ \\
\hline (c) Buffering-Hierarchical & $\begin{array}{l}\mathrm{S}-\mathrm{S}=\mathrm{SM}_{\mathrm{M}}-\mathrm{IF}_{\mathrm{F}}>\mathrm{IM}_{\mathrm{M}}-\mathrm{S}_{\mathrm{F}}>\mathrm{I}-\mathrm{I} \\
\quad \text { OR } \\
\mathrm{S}-\mathrm{S}=\mathrm{IM}_{\mathrm{M}}-\mathrm{S}_{\mathrm{F}}>\mathrm{S}_{\mathrm{M}-\mathrm{IF}_{\mathrm{F}}}>\mathrm{I}-\mathrm{I}\end{array}$ & $\begin{array}{l}\text { Secure attachment to only one parent (but not the other) leads to as good outcomes as secure } \\
\text { attachment to both parents. }\end{array}$ \\
\hline (d) Buffering-Horizontal & $\mathrm{S}-\mathrm{S}=\mathrm{S}_{\mathrm{M}}-\mathrm{IF}_{\mathrm{F}}=\mathrm{IM}_{\mathrm{M}}-\mathrm{S}_{\mathrm{F}}>\mathrm{I}-\mathrm{I}$ & $\begin{array}{l}\text { Secure attachment to either parent (but not the other) leads to as good outcomes as secure } \\
\text { attachment to both parents, all better than insecure attachment to both parents. }\end{array}$ \\
\hline
\end{tabular}

Note. Greater than symbols represent better developmental outcomes. S-S = Secure with mother and father; I-I = Insecure with mother and father; SM = Secure with mother; SF = Secure with father; IM = Insecure with mother; IF = Insecure with father. *All models assume that the I-I group has worse outcomes than the other three configuration groups. 


\section{References}

Abrams, K. Y. (2000). Pathways to disorganization: A study concerning varying types of parental frightened and frightening behaviors as related to infant disorganized attachment. University of California, Berkeley.

Abrams, K. Y., Rifkin, A., \& Hesse, E. (2006). Examining the role of parental frightened/frightening subtypes in predicting disorganized attachment within a brief observational procedure. Development and Psychopathology, 18(2), 345-361. https://doi.org/10.1017/S0954579406060184

Aiken, L. S., \& West, S. G. (1991). Multiple regression: Testing and interpreting interactions. Newbury, CA: Sage.

Ainsworth, M. D. S., Blehar, S., Waters, E., \& Wall, S. (1978). Patterns of attachment: A psychological study of the Strange Situation. Hillsdale, NJ: Erlbaum.

Arnott, B., \& Meins, E. (2007). Links among antenatal attachment representations, postnatal mindmindedness, and infant attachment security: A preliminary study of mothers and fathers. Bulletin of the Menninger Clinic, 71(2), 132-149.

Aviezer, O., Sagi, A., Resnick, G., \& Gini, M. (2002). School competence in young adolescence: Links to early attachment relationships beyond concurrent self-perceived competence and representations of relationships. International Journal of Behavioral Development, 26(5), 397-409. https://doi.org/10.1080/01650250143000328

Bakermans-kranenburg, M. J., Lotz, A., \& Dijk, K. A. (2019). Birth of a father: Fathering in the first 1,000 days. Child Development Perspectives, 0(0), 1-7. https://doi.org/10.1111/cdep.12347

Bar-Haim, Y., Aviezer, O., Berson, Y., \& Sagi, A. (2002). Attachment in infancy and personal space regulation in early adolescence. Attachment \& Human Development, 4(1), 68-83. https://doi.org/10.1080/14616730210123111

Belsky, J. (1981). Early human experience: A family perspective. Developmental Psychology, 17(1), 3-23. https://doi.org/10.1037/0012-1649.17.1.3

Belsky, J., \& Rovine, M. (1987). Temperament and attachment security in the strange situation: An empirical rapprochement. Child Development, 58(3), 787-795. https://doi.org/10.1111/14678624.ep7264801

Belsky, J. (1996). Parent, infant, and social-contextual antecedents of father-son attachment security. Developmental Psychology, 32(5), 905.

Belsky, J., Garduque, L., \& Hrncir, E. (1984). Assessing performance, competence, and executive capacity in infant play: Relations to home environment and security of attachment. Developmental Psychology, 20(3), 406-417. https://doi.org/10.1037/0012-1649.20.3.406

Belsky, J., \& Rovine, M. J. (1988). Nonmaternal care in the first year of life and the security of infantparent attachment. Child Development, 59(1), 157-167. https://doi.org/10.2307/1130397

Belsky, J., Spritz, B., \& Crnic, K. (1996). Infant attachment security and affective-cognitive information processing at age 3. Psychological Science. United Kingdom: Blackwell Publishing. https://doi.org/10.1111/j.1467-9280.1996.tb00339.x

Boldt, L. J., Kochanska, G., Grekin, R., \& Brock, R. L. (2016). Attachment in middle childhood: Predictors, correlates, and implications for adaptation. Attachment \& Human Development, 18(2), 115-140.

Boldt, L. J., Kochanska, G., \& Jonas, K. (2017). Infant attachment moderates paths from early negativity to preadolescent outcomes for children and parents. Child Development, 88(2), 584-596.

Boldt, L. J., Kochanska, G., Yoon, J. E., \& Koenig Nordling, J. (2014). Children's attachment to both parents from toddler age to middle childhood: Links to adaptive and maladaptive outcomes. Attachment and Human Development, 16(3), 211-229. https://doi.org/10.1080/14616734.2014.889181

Bowlby, J. (1969). Attachment and Loss, Vol. 1: Attachment. New York, NY: Basic Books. 
Bowlby, J. (1973). Attachment and Loss: Vol. 2. Separation: Anxiety and anger. New York, NY: Basic Books.

Bowlby, J. (1951). Maternal care and mental health. World Health Organization Monograph Series (Serial No. 2).

Bowlby, J. (1988). A secure base: Parent-child attachment and healthy human development. New York: Basic Books.

Braungart-Rieker, J., Courtney, S., \& Garwood, M. M. (1999). Mother-and father-infant attachment: Families in context. Journal of Family Psychology, 13(4), 535-553. https://doi.org/https://doi.org/10.1037/0893-3200.13.4.535

Braungart-Rieker, J. M., Zentall, S., Lickenbrock, D. M., Ekas, N. V, Oshio, T., \& Planalp, E. (2014). Attachment in the making: Mother and father sensitivity and infants' responses during the still-face paradigm. Journal of Eperimental Child Psychology, 125, 63-84.

Braungart-Rieker, J. M., Garwood, M. M., Powers, B. P., \& Wang, X. (2001). Parental sensitivity, infant affect, and affect regulation: Predictors of later attachment. Child Development, 72(1), 252-270.

Bretherton, I. (1985). Attachment theory: Retrospect and prospect. Monographs of the Society for Research in Child Development, 50(1-2), 3-35. https://doi.org/http://dx.doi.org.libproxy.newschool.edu/10.2307/3333824

Bretherton, I. (1991). Pouring new wine into old bottles: The social self as internal working model. In M. R. Gunnar \& L. A. Sroufe (Eds.), Minnesota symposia in child psychology: Self processes in development (pp. 1-41). Hillsdale, NJ: Erlbaum.

Bretherton, I. (1992). The origins of attachment theory. Developmental Psychology, 28(28), 759-775. https://doi.org/10.1037/0012-1649.28.5.759

Bretherton, I., \& Munholland, K. A. (2008). Internal working models in attachment relationships: Elaborating a central construct in attachment theory. In J. Cassidy \& P. R. Shaver (Eds.), Handbook of attachment: Theory, research and clinical applications (2nd editio, pp. 102-127). New York, NY: Guilford Press.

Brock, R. L., \& Lawrence, E. (2014). Intrapersonal, interpersonal, and contextual risk factors for overprovision of partner support in marriage. Journal of Family Psychology, 28(1), 54-64. https://doi.org/10.1037/a0035280

Brown, G. L., McBride, B. A., Bost, K. K., \& Shin, N. (2011). Parental involvement, child temperament, and parents' work hours: Differential relations for mothers and fathers. Journal of Applied Developmental Psychology, 32(6), 313-322. https://doi.org/10.1016/j.appdev.2011.08.004

Brown, G. L., Schoppe-Sullivan, S. J., Mangelsdorf, S. C., \& Neff, C. (2010). Observed and reported supportive coparenting as predictors of infant-mother and infant-father attachment security. Early Child Development and Care, 180(1-2), 121-137.

Bureau, J., Yurkowski, K., Schmiedel, S., Martin, J., Moss, E., \& Pallanca, D. (2014). Making children laugh: Parent-child dyadic synchrony and preschool attachment. Infant Mental Health Journal, 35(5), 482-494.

Bus, A. G., Belsky, J., van ljzendoom, M. H., \& Crnic, K. (1997). Attachment and bookreading patterns: A study of mothers, fathers, and their toddlers. Early Childhood Research Quarterly, 12(1), 81-98.

Caldera, Y. M., \& Lindsey, E. W. (2006). Coparenting, mother-infant interaction, and infant-parent attachment relationships in two-parent families. Journal of Family Psychology, 20(2), 275-283. https://doi.org/10.1037/0893-3200.20.2.275

Carlson, E. A., \& Sroufe, L. A. (1995). Contribution of attachment theory to developmental psychopathology. In D. Cicchetti \& D. Cohen (Eds.), Developmental Psychopathology: Vol. 1. Theory and methods (pp. 581-616). Oxford: Wiley.

Cassidy, J. (2016). The nature of the child's ties. In J. Cassidy \& P. R. Shaver (Eds.), Handbook of attachment: Theory, research and clinical applications (pp. 3-24; 3rd ed.). New York, NY: Guilford 
Press.

Cassidy, J., Jones, J. D., \& Shaver, P. R. (2013). Contributions of attachment theory and research: A framework for future research, translation, and policy. Development and Psychopathology, 25, 1415-1434. https://doi.org/10.1017/S0954579413000692

Chase-Lansdale, P. L., \& Owen, M. T. (1987). Maternal employment in a family context: Effects on infantmother and infant-father attachments. Child Development, 58(6), 1505-1512. https://doi.org/10.2307/1130690

Colonnesi, C., Wissink, I. B., Noom, M. J., Asscher, J. J., Hoeve, M., Stams, G. J. J. M., ... Kellaert-Knol, M. G. (2013). Basic Trust. Research on Social Work Practice, 23(2), 179-188. https://doi.org/10.1177/1049731512469301

Cooke, J. E., Kochendorfer, L. B., Stuart-Parrigon, K. L., Koehn, A. J., \& Kerns, K. A. (2018). Parent-child attachment and children's experience and regulation of emotion: A meta-analytic review. Emotion, 19(6), 1103-1126. https://doi.org/10.1037/emo0000504

Cooke, J. E., Stuart-parrigon, K. L., Movahed-abtahi, M., Koehn, A. J., Kerns, K. A., Cooke, J. E., ... Kerns, K. A. (2016). Children's emotion understanding and mother-child attachment: A meta-analysis. Emotion, 16(8), 1102-1106.

Cowan, P. A. (1997). Beyond Meta-Analysis: A Plea for a Family Systems View of Attachment. Child Development, 68(4), 601-603. https://doi.org/10.1111/j.1467-8624.1997.tb04222.x

Cox, M. J., Owen, M. T., Henderson, V. K., \& Margand, N. A. (1992). Prediction of infant-father and infant-mother attachment. Developmental Psychology, 28(3), 474-483. https://doi.org/10.1037/0012-1649.28.3.474

Coyl, D. D., Newland, L. A., \& Freeman, H. (2010). Predicting preschoolers' attachment security from parenting behaviours, parents' attachment relationships and their use of social support. Early Child Development and Care, 180(4), 499-512. https://doi.org/10.1080/03004430802090463

Cyr, C., Euser, E. M., Bakermans-Kranenburg, M. J., \& Van IJzendoorn, M. H. (2010). Attachment security and disorganization in maltreating and high-risk families: A series of meta-analyses. Development and Psychopathology, 22(1), 87-108. https://doi.org/10.1017/S0954579409990289

Dagan, O., \& Sagi-Schwartz, A. (2018). Early attachment network with mother and father: An unsettled issue. Child Development Perspectives, 12(2), 115-121. https://doi.org/10.1111/cdep.12272

Dagan, O., \& Sagi-Schwartz, A. (in press). Infant attachment (to mother and father) and its place in human development: Five decades of promising research (and an unsettled issue) (in press). In J. J. Lockman \& C. S. Tamis-LeMonda (Eds.), Cambridge handbook of infant development. Cambridge University Press.

Duschinsky, R. (2020). Cornerstones of attachment research. Oxford: Oxford University Press.Easterbrooks, M. A., \& Goldberg, W. A. (1984). Toddler development in the family: Impact of father involvement and parenting characteristics. Child Development, 55(3), 740-752. https://doi.org/10.2307/1130126

Edwards, E. P., Eiden, R. D., \& Leonard, K. E. (2004). Impact of fathers' alcoholism and associated risk factors on parent-infant attachment stability from 12 to 18 months. Infant Mental Health Journal, 25(6), 556-579. https://doi.org/10.1002/imhj.20027

Eagle, M. (2013) Attachment and Psychoanalysis, New York: Guilford

Ellis, B. J., Bianchi, J. M., Griskevicius, V., \& Frankenhuis, W. E. (2017). Beyond risk and protective factors: An adaptation-based approach to resilience. Perspectives on Psychological Science, 12(4), 561-587. https://doi.org/10.1177/1745691617693054

Fearon, R. P., Bakermans-Kranenburg, M. J., van IJzendoorn, M. H., Lapsley, A.-M., \& Roisman, G. I. (2010). The significance of insecure attachment and disorganization in the development of children's externalizing behavior: A meta-analytic study. Child Development, 81(2), 435-456. https://doi.org/10.1111/j.1467-8624.2009.01405.x 
Fonagy, P., Steele, M., Steele, H., Moran, G. S., \& Higgitt, A. C. (1991). The capacity for understanding mental states: The reflective self in parent and child and its significance for security of attachment. Infant Mental Health Journal, 12(3), 201-218.

Freitag, M. K., Belsky, J., Grossmann, K., Grossmann, K. E., \& Scheuerer-Englisch, H. (1996). Continuity in parent-child relationships from infancy to middle childhood and relations with friendship competence. Child Development, 67(4), 1437-1454. https://doi.org/10.2307/1131710

Fraley, R. C., \& Spieker, S. J. (2003). Are infant attachment patterns continuously or categorically distributed? A taxometric analysis of strange situation behavior. Developmental Psychology, 39(3), 387-404. https://doi.org/10.1037/0012-1649.39.3.387

Frodi, A. M., Lamb, M. E., Hwang, C. P., \& Frodi, M. (1983). Father-mother infant interaction in traditional and nontraditional Swedish families: A longtitudinal study. Alternative Lifestyles, 5(3), 142-163. https://doi.org/10.1007/BF01091325

Frosch, C. A., Cox, M. J., \& Goldman, B. D. (2001). Infant-parent attachment and parental and child behavior during parent-toddler storybook interaction. Merrill-Palmer Quarterly, 47(4), 445-474.

Fuertes, M., Faria, A., Beeghly, M., \& Lopes-dos-Santos, P. (2016). The effects of parental sensitivity and involvement in caregiving on mother-infant and father-infant attachment in a Portuguese sample. Journal of Family Psychology, 30(1), 147-156. https://doi.org/10.1037/fam0000139

Garwood, M. M. (1998). Parental sensitivity, parenting beliefs, and child temperament: Modeling effects on mother-and father-infant attachment. University of Notre Dame.

George, M. R. W. (2010). Parent-child attachment security and children's socio-emotional adjustment during the early school years. University of Notre Dame.

Goldberg, W. A., \& Easterbrooks, M. (1984). Role of marital quality in toddler development. Developmental Psychology, 20(3), 504-514. https://doi.org/https://doi.org/10.1037/00121649.20.3.504

Goossens, A., \& van IJzendoorn, M. H. (1990). Quality of infants' attachments to professional caregivers: Relation to infant-parent attachment and day-care characteristics. Child Development, 61(3), 832837. https://doi.org/10.2307/1130967

Granqvist, P., Hesse, E., Fransson, M., Main, M., Hagekull, B., \& Bohlin, G. (2016). Prior participation in the strange situation and overstress jointly facilitate disorganized behaviours: Implications for theory, research and practice. Attachment \& Human Development, 18(3), 235-249. https://doi.org/10.1080/14616734.2016.1151061

Groh, A. M., Fearon, R. P., Bakermans-Kranenburg, M. J., van IJzendoorn, M. H., Steele, R. D., \& Roisman, G. I. (2014). The significance of attachment security for children's social competence with peers: a meta-analytic study. Attachment \& Human Development, 16(2), 103-136. https://doi.org/10.1080/14616734.2014.883636

Groh, A. M., Fearon, R. M. P., van IJzendoorn, M. H., Bakermans-Kranenburg, M. J., \& Roisman, G. I. (2017). Attachment in the early life course: Meta-analytic evidence for its role in socioemotional development. Child Development Perspectives, 11(1), 70-76. https://doi.org/10.1111/cdep.12213

Groh, A. M., Propper, C., Mills-Koonce, R., Moore, G. A., Calkins, S., \& Cox, M. (2019). Mothers' physiological and affective responding to infant distress: unique antecedents of avoidant and resistant attachments. Child Development, 90(2), 489-505. https://doi.org/10.1111/cdev.12912

Groh, A. M., Roisman, G. I., van IJzendoorn, M. H., Bakermans-Kranenburg, M. J., \& Fearon, R. P. (2012). The significance of insecure and disorganized attachment for children's internalizing symptoms: A meta-analytic study. Child Development, 83(2), 591-610. https://doi.org/10.1111/j.14678624.2011.01711.x

Grossmann, K. E., Grossmann, K., Huber, F., \& Wartner, U. (1981). German children's behavior towards their mothers at 12 months and their fathers at 18 months in Ainsworth's Strange Situation. International Journal of Behavioral Development, 4, 157-181. 
Grossmann, K., Grossmann, K. E., Fremmer-Bombik, E., Kindler, H., Scheuerer-Englisch, H., \& Zimmermann, P. (2002). The uniqueness of the child-father attachment relationship: Fathers' sensitive and challenging play as a pivotal variable in a 16-year longitudinal study. Social Development, 11(3), 307-331. https://doi.org/10.1111/1467-9507.00202

Heidt-Kozisek, E., Pipp-Siegel, S., Easterbrooks, M. A., \& Harmon, R. J. (1997). Knowledge of self, mother, and father in preterm and full-term toddlers. Infant Behavior and Development, 20(3), 311-324. https://doi.org/https://doi.org/10.1016/S0163-6383(97)90003-5

Hesse, E., \& Main, M. (2006). Frightened, threatening, and dissociative parental behavior in low-risk samples: Description, discussion, and interpretations. Development and Psychopathology, 18(2), 309-343. https://doi.org/10.1017/S0954579406060172

Hinshaw-Fuselier, S. S. (2004). Pathways to disorganized attachment in infancy: Are maternal depressed mood and disruptive life events meaningful contributors? The University of Texas at Austin.

Ioannidis, J. P. A. (2017). Meta-analyses can be credible and useful: A new standard. JAMA Psychiatry, 74(4), 311-312. https://doi.org/10.1001/jamapsychiatry.2017.0035

Jardin, C., Venta, A., Newlin, E., Ibarra, S., \& Sharp, C. (2017). Secure attachment moderates the relation of sexual trauma with trauma symptoms among adolescents from an inpatient psychiatric facility. Journal of Interpersonal Violence, 32(10), 1565-1585. https://doi.org/10.1177/0886260515589928

Joseph, M., O'Connor, T., Briskman, J., Maughan, B., \& Scott, S. (2014). The formation of secure new attachments by children who were maltreated: An observational study of adolescents in foster care. Development and Psychopathology, 26(1), 67-80. https://doi.org/doi:10.1017/S0954579413000540

Kazura, K. (2000). Fathers' qualitative and quantitative involvement: An investigation of attachment, play, and social interactions. The Journal of Men's Studies, 9(1), 41-57.

Kennedy, M., Betts, L., Dunn, T., Sonuga-Barke, E., \& Underwood, J. (2015). Applying Pleck's model of paternal involvement to the study of preschool attachment quality: A proof of concept study. Early Child Development and Care, 185(4), 601-613.

Kerns, K. A., Tomich, P. L., Aspelmeier, J. E., \& Contreras, J. M. (2000). Attachment-based assessments of parent-child relationships in middle childhood. Developmental Psychology, 36(5), 614-626. https://doi.org/10.1037//0012-1649.36.5.614

Kim, S., Kochanska, G., Boldt, L. J., Nordling, J. K., \& O’Bleness, J. J. (2014). Developmental trajectory from early responses to transgressions to future antisocial behavior: Evidence for the role of the parent-child relationship from two longitudinal studies. Development and Psychopathology, 26(1), 93-109. https://doi.org/10.1017/S0954579413000850

Kochanska, G., Aksan, N., \& Carlson, J. J. (2005). Temperament, relationships, and young children's receptive cooperation with their parents. Developmental Psychology, 41(4), 648-660. https://doi.org/10.1037/0012-1649.41.4.648

Kochanska, G., \& Kim, S. (2012). Toward a new understanding of legacy of early attachments for future antisocial trajectories: Evidence from two longitudinal studies. Development and Psychopathology, 24(3), 783-806. https://doi.org/10.1017/S0954579412000375

Kochanska, G., \& Kim, S. (2013). Early attachment organization with both parents and future behavior problems: From infancy to middle childhood. Child Development, 84(1), 283-296. https://doi.org/10.1111/j.1467-8624.2012.01852.x

Kochanska, G., Woodard, J., Kim, S., Koenig, J. L., Yoon, J. E., \& Barry, R. A. (2010). Positive socialization mechanisms in secure and insecure parent-child dyads: Two longitudinal studies. Journal of Child Psychology and Psychiatry, 51(9), 998-1009.

Kozlowska, K., \& Hanney, L. (2002). The network perspective: An integration of attachment and family systems theories. Family Process, 41(3), 285-312. https://doi.org/10.1111/j.1545$\underline{5300.2002 .41303 . x}$ 
Lakens, D. (2017). Equivalence tests: A practical primer for $\mathrm{t}$ tests, correlations, and meta-analyses. Social Psychological and Personality Science, 8(4), 355-362. https://doi.org/10.1177/1948550617697177

Lamb, M. E. (1978). Qualitative aspects of mother- and father-infant attachments. Infant Behavior and Development, 1, 265-275. https://doi.org/https://doi.org/10.1016/S0163-6383(78)80038-1

Lamb, M. E., Hwang, C. P., Frodi, A. M., \& Frodi, M. (1982). Security of mother- and father-infant attachment and its relation to sociability with strangers in traditional and nontraditional Swedish families. Infant Behavior and Development, 5(2-4), 355-367. https://doi.org/10.1016/S01636383(82)80046-5

Lau, J., loannidis, J. P. A., \& Schmid, C. H. (1998). Summing up evidence: One answer is not always enough. The Lancet, 351(9096), 123-127.

Laurent, H. K., Kim, H. K., \& Capaldi, D. M. (2008). Prospective effects of interparental conflict on child attachment security and the moderating role of parents' romantic attachment. Journal of Family Psychology, 22(3), 377-388. https://doi.org/10.1037/0893-3200.22.3.377

Lehman, E. B., Denham, S. A., Moser, M. H., \& Reeves, S. L. (1992). Soft object and pacifier attachments in young children: The role of security of attachment to the mother. Child Psychology \& Psychiatry \& Allied Disciplines. United Kingdom: Pergamon Press. https://doi.org/10.1111/j.14697610.1992.tb00939.x

Lickenbrock, D. M. (2010). Examining infant attachment security with mothers and fathers: An ecological systems perspective. University of Notre Dame.

Lickenbrock, D. M., \& Braungart-Rieker, J. M. (2015). Examining antecedents of infant attachment security with mothers and fathers: An ecological systems perspective. Infant Behavior and Development, 39, 173-187.

Lickenbrock, D. M., Braungart-Rieker, J. M., Ekas, N. V, Zentall, S. R., Oshio, T., \& Planalp, E. M. (2013). Early temperament and attachment security with mothers and fathers as predictors of toddler compliance and noncompliance. Infant and Child Development, 22(6), 580-602.

Lindsey, E. W., \& Caldera, Y. M. (2015). Shared affect and dyadic synchrony among secure and insecure parent-toddler dyads. Infant and Child Development, 24(4), 394-413.

Lindsey, E. W., Caldera, Y. M., \& Tankersley, L. (2009). Marital conflict and the quality of young children's peer play behavior: The mediating and moderating role of parent-child emotional reciprocity and attachment security. Journal of Family Psychology, 23(2), 130-145. https://doi.org/10.1037/a0014972

Lionetti, F. (2014). What promotes secure attachment in early adoption? The protective roles of infants' temperament and adoptive parents' attachment. Attachment \& Human Development, 16(6), 573589.

Lundy, B. L. (2002). Paternal socio-psychological factors and infant attachment: The mediating role of synchrony in father-infant interactions. Infant Behavior and Development, 25(2), 221-236

Lyons-Ruth, K., Pechtel, P., Yoon, S. A., Anderson, C. M., \& Teicher, M. H. (2016). Disorganized attachment in infancy predicts greater amygdala volume in adulthood. Behavioural Brain Research, 308, 83-93. https://doi.org/10.1016/j.bbr.2016.03.050

Madigan, S., Atkinson, L., Laurin, K., \& Benoit, D. (2013). Attachment and internalizing behavior in early childhood: A meta-analysis. Developmental Psychology, 49(4), 672-689.

https://doi.org/10.1037/a0028793

Madigan, S., Benoit, D., \& Boucher, C. (2011). Exploration of the links among fathers' unresolved states of mind with respect to attachment, atypical paternal behavior, and disorganized infant-father attachment. Infant Mental Health Journal, 32(3), 286-304.

Main, M. (2000). The organized categories of infant, child, and adult attachment: Flexible vs. inflexible attention under attachment-related stress. Journal of the American Psychoanalytic Association, 
48(4), 1055-1096; discussion 1175-1187. https://doi.org/10.1177/00030651000480041801

Main, M., \& Cassidy, J. (1988). Categories of response to reunion with the parent at age 6: Predictable from infant attachment classifications and stable over a 1-month period. Developmental Psychology, 24(3), 415.

Main, M., Kaplan, N., \& Cassidy, J. (1985). Security in infancy, childhood, and adulthood: A move to the level of representation. Monographs of the Society for Research in Child Development, 50(1-2), 66104. https://doi.org/http://dx.doi.org.libproxy.newschool.edu/10.2307/3333827

Main, M., \& Solomon, J. (1986). Discovery of an insecure-disorganized/disoriented attachment pattern. In T. B. Brazelton \& M. Yogman (Eds.), Affective development in infancy (pp. 95-124). Norwood, NJ: Ablex.

Main, M., \& Weston, D. R. (1981). The quality of the toddler's relationship to mother and to father: Related to conflict behavior and the readiness to establish new relationships. Child Development, 52(3), 932-940.

McElwain, N. L. (1999). Correlates and antecedents of preschool children's friendship relations: An examination of emotion regulation, social understanding, and family relationships. University of Michigan.

McElwain, N. L., \& Volling, B. L. (2004). Attachment security and parental sensitivity during infancy: Associations with friendship quality and false-belief understanding at age 4. Journal of Social and Personal Relationships, 21(5), 639-667.

Moilanen, I., Kunelius, A., Tirkkonen, T., \& Crittenden, P. M. (2000). Attachment in Finnish twins. In P. M. Crittenden \& A. H. Claussen (Eds.), The organization of attachment relationships: Maturation, culture and context (pp. 125-140). Cambridge University Press Cambridge, UK.

Monteiro, Ligia, Veríssimo, M., Vaughn, B. E., Santos, A. J., \& Bost, K. K. (2008). Secure base representations for both fathers and mothers predict children's secure base behavior in a sample of Portuguese families. Attachment \& Human Development, 10(2), 189-206. https://doi.org/10.1080/14616730802113711

Monteiro, Lígia, Veríssimo, M., Vaughn, B. E., Santos, A. J., Torres, N., \& Fernandes, M. (2010). The organization of children's secure base behaviour in two-parent Portuguese families and father's participation in child-related activities. European Journal of Developmental Psychology, 7(5), 545560.

Moore, G. A., Cohn, J. F., Belsky, J., \& Campbell, S. B. (1996). A comparison of traditional and quantitative classification of attachment status. Infant Behavior and Development, 19(2), 265-268.

Notaro, P. C., \& Volling, B. L. (1999). Parental responsiveness and infant-parent attachment: A replication study with fathers and mothers. Infant Behavior and Development, 22(3), 345-352.

Oppenheim, D., Sagi, A., \& Lamb, M. E. (1988). Infant-adult attachments on the kibbutz and their relation to socioemotional development 4 years later. Developmental Psychology, 24(3), 427-433. https://doi.org/10.1037/0012-1649.24.3.427

Owen, M. T., Easterbrooks, M. A., Chase-Lansdale, L., \& Goldberg, W. A. (1984). The relation between maternal employment status and the stability of attachments to mother and to father. Child Development, 55(5), 1894-1901. https://doi.org/10.1111/j.1467-8624.1984.tb00431.x

Owen, Margaret Tresch. (1981). Similarity between infant-mother and infant-father attachments. University of Michigan, ProQuest Dissertations Publishing.

Owen, Margaret Tresch, \& Cox, M. J. (1997). Marital conflict and the development of infant-parent attachment relationships. Journal of Family Psychology, 11(2), 152-164. https://doi.org/10.1037/0893-3200.11.2.152

Pallini, S., Chirumbolo, A., Morelli, M., Baiocco, R., Laghi, F., \& Eisenberg, N. (2018). The relation of attachment security status to effortful self-regulation: A meta-analysis. Psychological Bulletin, 144(5), 501-531. https://doi.org/10.1037/bul0000134 
Parker, K., \& Wang, W. (2013). Modern parenthood. Roles of moms and dads converge as they balance work and family. Pew Research Center. Available at:

https://www.pewsocialtrends.org/2013/03/14/modern-parenthood-roles-of-moms-and-dadsconverge-as-they-balance-work-and-family/

Pipp, S., Easterbrooks, M. A., \& Brown, S. R. (1993). Attachment status and complexity of infants' selfand other-knowledge when tested with mother and father. Social Development, 2(1), 1-14. https://doi.org/10.1111/j.1467-9507.1993.tb00001.x

Planalp, E. M., \& Braungart-Rieker, J. M. (2013). Temperamental precursors of infant attachment with mothers and fathers. Infant Behavior and Development, 36(4), 796-808.

Renk, K., Roberts, R., Roddenberry, A., Luick, M., Hillhouse, S., Meehan, C., ... Phares, V. (2003). Mothers, fathers, gender role, and time parents spend with their children. Sex Roles, 48(7-8), 305-315.

Richters, J., Waters, E., \& Vaughn, B. (1988). Empirical classification of infant-mother relationships from interactive behavior and crying during reunion. Child Development, 59, 512-522.

Riley, R. D., Lambert, P. C., \& Abo-Zaid, G. (2010). Meta-analysis of individual participant data: rationale, conduct, and reporting. BMJ, 340, c221. https://doi.org/10.1136/bmj.c221

Roisman, G. I., Newman, D. A., Fraley, R. C., Haltigan, J. D., Groh, A. M., \& Haydon, K. C. (2012). Distinguishing differential susceptibility from diathesis-stress: Recommendations for evaluating interaction effects. Development and Psychopathology, 24(2), 389-409. https://doi.org/10.1017/S0954579412000065

Rosen, K. S., \& Rothbaum, F. (1993). Quality of parental caregiving and security of attachment. Developmental Psychology. US: American Psychological Association. https://doi.org/10.1037/00121649.29.2.358

Sagi-Schwartz, A., \& Aviezer, O. (2005). Correlates of attachment to multiple caregivers in kibbutz children from birth to emerging adulthood: The Haifa longitudinal study. In K. E. Grossmann, K. Grossmann, \& E. Waters (Eds.), Attachment from infancy to adulthood (pp. 165-197). New York, NY: Guilford Press.

Sagi-Schwartz, A., Lamb, M. E., Lewkowicz, K. S., Shoham, R., Dvir, R., \& Estes, D. (1985). Security of infant-mother, -father, and -metapelet attachments among kibbutz-reared Israeli children. Monographs of the Society for Research in Child Development, 50(1-2), 257-275. https://doi.org/doi:10.2307/3333837

Sagi, A., Lamb, M. E., \& Gardner, W. (1986). Relations between Strange Situation behavior and stranger sociability among infants on Israeli kibbutzim. Infant Behavior and Development, 9(3), 271-282.

Schneider Rosen, K., \& Burke, P. B. (1999). Multiple attachment relationships within families: Mothers and fathers with two young children. Developmental Psychology, 35(2), 436.

Schoppe-Sullivan, S. J., Diener, M. L., Mangelsdorf, S. C., Brown, G. L., McHale, J. L., \& Frosch, C. A. (2006). Attachment and sensitivity in family context: The roles of parent and infant gender. Infant and Child Development, 15(4), 367-385.

Schneider Rosen, K., \& Burke, P. B. (1999). Multiple attachment relationships within families: Mothers and fathers with two young children. Developmental Psychology, 35(2), 436-444. https://doi.org/https://doi.org/10.1037/0012-1649.35.2.436

Schuengel, C., Bakermans-Kranenburg, M. J., \& Van IJzendoorn, M. H. (1999). Frightening maternal behavior linking unresolved loss and disorganized infant attachment. Journal of Consulting and Clinical Psychology, 67(1), 54-63. https://doi.org/10.1080/02646839808404575

Solomon, J., \& George, C. (1999). The development of attachment in separated and divorced families. Attachment \& Human Development, 1(1), 2-33. https://doi.org/10.1080/14616739900134011

Steele, H., Steele, M., Croft, C., \& Fonagy, P. (1999). Infant-mother attachment at one year predicts children's understanding of mixed emotions at six years. Social Development, 8(2), 161-178. https://doi.org/10.1111/1467-9507.00089 
Steele, H., Steele, M., \& Fonagy, P. (1996). Associations among attachment classifications of mothers, fathers, and their infants. Child Development, 67(2), 541-555. https://doi.org/10.1111/j.14678624.1996.tb01750.x

Steele, Howard, Steele, M., \& Croft, C. (2008). Early attachment predicts emotion recognition at 6 and 11 years old. Attachment \& Human Development, 10(4), 379-393.

Stewart, L. A., \& Tierney, J. F. (2002). To IPD or not to IPD? Advantages and disadvantages of systematic reviews using individual patient data. Evaluation \& The Health Professions, 25(1), 76-97.

Sroufe, A. L., Egeland, B., Carlson, E. A., \& Collins, W. A. (2005). Placing early attachment experiences in developmental context. In K. E. Grossmann, K. Grossmann, \& E. Waters (Eds.), Attachment from infancy to adulthood: The major longitudinal studies (pp. 48-70). New York: Guilford Publications.

Sroufe, L. A., \& Waters, E. (1977). Attachment as an organizational construct. Child Development, 48(4), 1184. https://doi.org/10.2307/1128475

Suess, G. J., Grossmann, K. E., \& Sroufe, L. (1992). Effects of infant attachment to mother and father on quality of adaptation in preschool: From dyadic to individual organisation of self. International Journal of Behavioral Development, 15(1), 43-65.

Tirkkonen, T., Joskitt, L., Kunelius, A., Huhtaniska, M., Ebeling, H., \& Moilanen, I. (2016). Twinship as a protective factor against behavioural and emotional problems at preschool age. Early Child Development and Care, 186(6), 863-878. https://doi.org/10.1080/03004430.2015.1066783

Tluczek, A., Clark, R., McKechnie, A. C., \& Brown, R. L. (2015). Factors affecting parent-child relationships one year after positive newborn screening for cystic fibrosis or congenital hypothyroidism. Journal of Developmental and Behavioral Pediatrics, 36(1), 1-11. https://doi.org/10.1097/DBP.0000000000000112

Umemura, T., Jacobvitz, D., Messina, S., \& Hazen, N. (2013). Do toddlers prefer the primary caregiver or the parent with whom they feel more secure? The role of toddler emotion. Infant Behavior \& Development, 36(1), 102-114. https://doi.org/10.1016/i.infbeh.2012.10.003

van Ee, E., Kleber, R. J., Jongmans, M. J., Mooren, T. T. M., \& Out, D. (2016). Parental PTSD, adverse parenting and child attachment in a refugee sample. Attachment \& Human Development, 18(3), 273-291. https://doi.org/10.1080/14616734.2016.1148748

van IJzendoorn, M. H., Sagi, A., \& Lambermon, M. W. E. (1992). The multiple caretaker paradox: Data from Holland and Israel. New Directions for Child and Adolescent Development, 1992(57), 5-24. https://doi.org/10.1002/cd.23219925703

van IJzendoorn, M. H., Dijkstra, J., \& Bus, A. G. (1995). Attachment, intelligence, and language: A metaanalysis. Social Development, 4(2), 115-128. https://doi.org/10.1111/j.1467-9507.1995.tb00055.x

van ljzendoorn, M. H., Schuengel, C., \& Bakermans-Kranenburg, M. J. (1999). Disorganized attachment in early childhood: meta-analysis of precursors, concomitants, and sequelae. Development and Psychopathology, 11(2), 225-249.

Verhage, M. L., Fearon, R. M. P., Schuengel, C., van IJzendoorn, M. H., Bakermans-Kranenburg, M. J., Madigan, S., ... Synthesis, T. C. on A. T. (2018). Examining ecological constraints on the intergenerational transmission of attachment via individual participant data meta-analysis. Child Development, 89(6), 2023-2037. https://doi.org/10.1111/cdev.13085

Verhage, M. L., Schuengel, C., Duschinsky, R., van IJzendoorn, M. H., Fearon, R. M. P., Madigan, S., Roisman, G. I., Bakermans-Kranenburg, M. J., \& the Collaboration on Attachment Transmission Synthesis (in-press). The collaboration on attachment transmission synthesis (CATS): A move to the level of individual participant data meta-analysis. Current Directions in Psychological Science.

Veríssimo, M., Santos, A. J., Vaughn, B. E., Torres, N., Monteiro, L., \& Santos, O. (2011). Quality of attachment to father and mother and number of reciprocal friends. Early Child Development and Care, 181(1), 27-38.

Volling, B. L. (2001). Early attachment relationships as predictors of preschool children's emotion 
regulation with a distressed sibling. Early Education and Development, 12(2), 185-207. https://doi.org/10.1207/s15566935eed1202_2

Volling, B. L., \& Belsky, J. (1992). The contribution of mother-child and father-child relationships to the quality of sibling interaction: A longitudinal study. Child Development, 63(5), 1209-1222.

Volling, B. L., Yu, T., Gonzalez, R., Kennedy, D. E., Rosenberg, L., \& Oh, W. (2014). Children's responses to mother-infant and father-infant interaction with a baby sibling: Jealousy or joy? Journal of Family Psychology, 28(5), 634-644. https://doi.org/10.1037/a0037811

Wille, D. E. (1998). Longitudinal analysis of mothers' and fathers' responses on the maternal separation anxiety scale. Merrill-Palmer Quarterly, 44(2), 216-233.

Waters, E., \& Deane, K. E. (1985). Defining and assessing individual differences in attachment relationships: Q-methodology and the organization of behavior in infancy and early childhood. Monographs of the Society for Research in Child Development, 50(1-2), 41-65. https://doi.org/http://dx.doi.org.libproxy.newschool.edu/10.2307/3333826

Wong, M. S., Mangelsdorf, S. C., Brown, G. L., Neff, C., \& Schoppe-Sullivan, S. J. (2009). Parental beliefs, infant temperament, and marital quality: Associations with infant-mother and infant-father attachment. Journal of Family Psychology, 23(6), 828-838. https://doi.org/10.1037/a0016491

Youngblade, L. M., \& Belsky, J. (1992). Parent-child antecedents of 5-year-olds' close friendships: A longitudinal analysis. Developmental Psychology, 28(4), 700-713.

Youngblade, L. M., \& Belsky, J. (1995). From family to friend: Predicting positive dyadic interaction with a close friend at 5 years of age from early parent-child relations. In S. Shulman (Ed.), Human development, Vol. 7. Close relationships and socioemotional development (pp. 35-61). Ablex Publishing.

Youngblade, L. M., Park, K. A., \& Belsky, J. (1993). Measurement of young children's close friendship: A comparison of two independent assessment systems and their associations with attachment security. International Journal of Behavioral Development, 16(4), 563-587.

Zentall, S. R., Braungart-Rieker, J. M., Ekas, N. V, \& Lickenbrock, D. M. (2012). Longitudinal assessment of sleep-wake regulation and attachment security with parents. Infant and Child Development, 21(5), 443-457. 